\title{
Solvent-Free Synthesis and Thin-Film Deposition of Cesium Copper Halides with Bright Blue Photoluminescence
}

\author{
Paz Sebastia-Luna, Javier Navarro-Alapont, Michele Sessolo, Francisco Palazon*, and Henk J. Bolink \\ Instituto de Ciencia Molecular, ICMol, Universidad de Valencia, C/ Catedrático J. Beltrán 2, 46980 Paterna, Spain
}

\begin{abstract}
Non-toxic alternatives to lead halide perovskites are highly sought after for applications in optoelectronics. Blue-luminescent materials are especially demanded as they could be used to prepare white light-emitting diodes, with important potential applications in lighting systems. However, wide bandgap blue emitters with high photoluminescence quantum yields (PLQY) are typically more difficult to obtain as compared to green- or red-emitting ones. Here, we prepared two series of inorganic cesium copper halides, with the general formulas $\mathrm{Cs}_{3} \mathrm{Cu}_{2} \mathrm{X}_{5}$ and $\mathrm{CsCu}_{2} \mathrm{X}_{3}(\mathrm{X}=\mathrm{Cl}, \mathrm{Br}, \mathrm{I}$, and mixtures thereof) by dry mechanochemical synthesis at room temperature. X-ray diffraction demonstrates quantitative conversion of binary precursors into the desired ternary structures and good halide mixing in single-phase compounds. We identified $\mathrm{Cs}_{3} \mathrm{Cu}_{2} \mathrm{I}_{5}$ as the most promising material as it maintains blue luminescence centered at $442 \mathrm{~nm}$ with high PLQY (>40\%) after several days in air $\left(\mathrm{Cs}_{3} \mathrm{Cu}_{2} \mathrm{Cl}_{5}\right.$ shows significantly higher PLQY over $80 \%$ but is unstable in air). Based on this, we fabricated homogeneous and pinhole-free $\mathrm{Cs}_{3} \mathrm{Cu}_{2} \mathrm{I}_{5}$ thin films by thermal single-source vacuum deposition. Crystalline phase and photoluminescence are maintained in the thin films, validating that these low-toxicity materials can be synthesized and processed by fully solvent-free routes for a widespread implementation in optoelectronic devices.
\end{abstract}

\section{INTRODUCTION}

In the past decade, lead halide perovskites (LHPs) have emerged as promising materials for optoelectronics. ${ }^{1-4}$ Driven by their thrust, there is a growing interest in developing alternative multinary metal halides (MMHs), of which LHPs represent a subclass. Indeed, the necessity of replacing toxic $\mathrm{Pb}^{2+}$ ions by other more environmentally-friendly metals requires to search for different ternary and quaternary MMHs, with various stoichiometries and crystal structures. ${ }^{5,6}$ Among these, $\mathrm{Cu}(\mathrm{I})$-based fully-inorganic ternary metal halides are particularly promising, especially for applications in lightemitting diodes (LEDs). ${ }^{7-9}$ Stable crystals with two different stoichiometries can be formed: $\mathrm{CsCu}_{2} \mathrm{X}_{3}$ and $\mathrm{Cs}_{3} \mathrm{Cu}_{2} \mathrm{X}_{5}(\mathrm{X}=\mathrm{Cl}, \mathrm{Br}$, I, or mixtures thereof). The most common crystal structure of both compounds at room temperature is depicted in Figure 1.
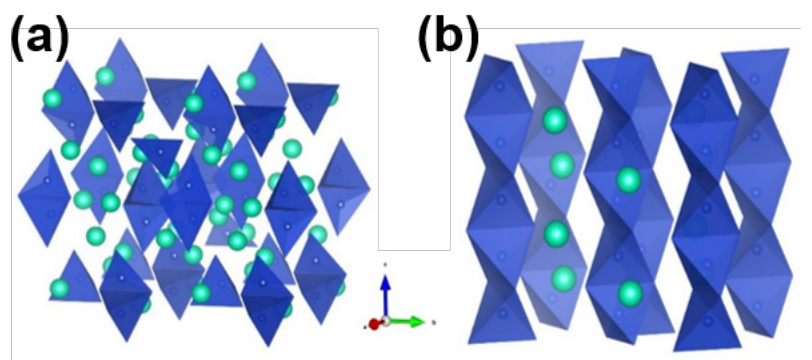

Figure 1. Crystal structures of $\mathrm{Cs}_{3} \mathrm{Cu}_{2} \mathrm{Br}_{5}$ (left) and $\mathrm{CsCu}_{2} \mathrm{Br}_{3}$ (right), created with VESTA software based on crystallographic information files obtained in the Inorganic Crystal Structure Database (refs: 150297 and 49613). Green balls represent $\mathrm{Cs}^{+}$ions and blue polygons represent $\mathrm{CuBr}_{4}$ tetrahedra.

$\mathrm{Cu}(\mathrm{I})$ is in tetrahedral coordination with the halides in both cases. However, $\mathrm{Cs}_{3} \mathrm{Cu}_{2} \mathrm{X}_{5}$ is constituted by isolated dimers of $\mathrm{CuX}_{4}$ whereas $\mathrm{CsCu}_{2} \mathrm{X}_{3}$ consists of side-sharing tetrahedra spatially arranged as wires. Based on these considerations, these structures may be referred to as $0 \mathrm{D}$ and $1 \mathrm{D}$ respectively. ${ }^{9}$ To the best of our knowledge, only a few reports on these compounds exist. ${ }^{9-12}$ Furthermore, in the above-mentioned publications, the synthesis and thin film deposition of such MMHs was carried out either by solution processes in (toxic) organic solvents or by highly time- and energy-consuming thermal routes. Lately, solvent-free mechanochemical synthesis (MCS) has been shown to be a very simple and efficient approach to synthesize different phase-pure multinary metal halides. ${ }^{13-21}$ This technique can be considered green chemistry, as it does not involve the use of solvents, toxic compounds, high temperatures, and it avoids the waste of materials and derivatives during the process. ${ }^{22}$ Although the exact mechanisms and reaction kinetics happening during MCS are not fully elucidated, as this would require among others the possibility to monitor the process in-situ through different characterization methods (something that is far from trivial experimentally), ${ }^{23}$ we demonstrate that this process enables the formation of $\mathrm{Cu}(\mathrm{I})$ ternary inorganic halides of high quality. In particular, some of the as-synthesized compounds exhibit bright photoluminescence even as non-passivated bulk powders, and are stable in air for several days. Furthermore, as-synthesized compounds can be deposited as thin films with good morphology, crystallinity and photoluminescence. In order to do so, we employed single-source vacuum deposition (SSVD) which has recently proven to be an easy, fast and non-toxic (solvent-free) approach for the deposition of other inorganic as well as hybrid organic-inorganic halide compounds..$^{17,24,25}$

\section{EXPERIMENTAL SECTION}

Materials. Cesium chloride $(\mathrm{CsCl},>99 \%)$, cesium bromide $(\mathrm{CsBr}$, $>99 \%$ ) and cesium iodide (CsI, > $99 \%$ ) were purchased from TCI. 
Copper(I) chloride ( $\mathrm{CuCl}, \geq 99,999 \%)$, copper(I) bromide (CuBr, $\geq 99,999 \%$ ) and copper(I) iodide (CuI, $\geq 99.999 \%$ ) were purchased from Sigma-Aldrich. Dimethyl sulfoxide (DMSO) reagent grade was purchased from Scharlau and N,N-dimethylformamide (DMF) from Fisher. All chemicals were stored in a nitrogen-filled glovebox and used as received without further purification.

Mechanochemical Synthesis. Stoichiometric amounts of CsX:CuX powders were mixed inside a nitrogen-filled glovebox. Then, approximately 3 grams of the mixed precursors powders was introduced inside $10 \mathrm{~mL}$ zirconia ball-mill jars with 2 zirconia beads of $10 \mathrm{~mm}$ in diameter. The jars were closed under nitrogen so that the powders were not exposed to air. Then ball-milling was performed with a MM-400 shaking ball-mill from Retsch, at a frequency of $30 \mathrm{~Hz}$ for 99 minutes.

Thin-film deposition by solution processing. Deposition and characterization of the thin films were carried out inside a cleanroom ISO 7 10000. Glass substrates were extensively cleaned using subsequent sonication in water with soap, deionized water and 2propanol baths. After drying with an $\mathrm{N}_{2}$ flow, the substrates were placed in a UV Ozone cleaner for 15 minutes. Substrates were transferred to a nitrogen-filled glovebox $\left(\mathrm{H}_{2} \mathrm{O}\right.$ and $\left.\mathrm{O}_{2}<0.1 \mathrm{ppm}\right)$ for the solution processing of the films. $\mathrm{Cs}_{3} \mathrm{Cu}_{2} \mathrm{I}_{5}$ powders were dissolved into a mixed solvent containing DMF and DMSO with a volume ratio of $1: 1$ to a $0.7 \mathrm{M}$ concentration. The solutions were then filtered through a with a $0.45 \mu \mathrm{m}$ pore size polytetrafluoroethylene (PTFE) filter. Thin-films were deposited by spin-coating at a speed of 3000 rpm for $60 \mathrm{~s}$, followed by annealing on a hot plate at $100{ }^{\circ} \mathrm{C}$ for 60 $\min$.

Single-source vacuum deposition. In a typical deposition, an alumina thermal source (Creaphys $\mathrm{GmbH}$ ) inside a home-made vacuum chamber was loaded with 0.5 grams of mechanochemically synthesized $\mathrm{Cs}_{3} \mathrm{Cu}_{2} \mathrm{I}_{5}$ powder. The chamber was then evacuated to a pressure of $8 \cdot 10^{-6} \mathrm{mbar}$ and the source was rapidly heated to $600{ }^{\circ} \mathrm{C}$ with a ramp of $50^{\circ} \mathrm{C} / \mathrm{min}$. The deposition is controlled by a quartz microbalance sensor and stopped after the complete evaporation of the solid.

XRD characterization. $X$-ray diffraction was measured with a powder diffractometer model D8 Advance A25 Bruker brand equipped with $\mathrm{CuKa}$ anode. Single scans were acquired in the $2 \theta=10^{\circ}$ to $40^{\circ}$ range with a step size of $2 \theta=0.025^{\circ}$, in Bragg-Brentano geometry in air. Whole powder pattern decompositions (WPPD) using the socalled Le Bail method, implemented in Fullprof software, were applied for the refinement of unit cell parameters. ${ }^{1}$ Thompson-CoxHastings pseudo-Voigt line profile with refinable lineshape parameters are assumed for the fittings. ${ }^{2}$

Optical characterization. UV-visible absorption spectra of the films and powders were collected using a Jasco V-670 UV/Vis/NIR spectrophotometer (Jasco, Easton, USA). The photoluminescence characteristics for powders were studied using a xenon lamp coupled to a monochromator as the excitation source, and an integrated sphere coupled to a spectrometer Hamamatsu C9920-02 with a Hamamatsu PMA-11 optical detector (Hamamatsu Photonics K.K.), in order to quantitatively determine the PLQY. For a typical analysis, three scans with an integration time of $100 \mathrm{~ms}$ were collected and averaged. Emission and excitation spectra were measured with a spectrofluorometer Fluoromax Horiba-MTB equipped with a xenon light source coupled to a monochromator.

Scanning Electron Microscopy (SEM). The SEM images were obtained using a Hitachi S-4800 Scanning-Electron Microscope, operating at an accelerating voltage of $20 \mathrm{kV}$ over platinum-metallized samples.

Thermal characterization. Thermogravimetric analysis was carried out with a TA Discovery TGA550 (TA Instruments) equipped with a continuous nitrogen flow. Measurements were performed with a ramp of $10^{\circ} \mathrm{C} / \mathrm{min}$ from room temperature to $600^{\circ} \mathrm{C}$.

\section{RESULTS AND DISCUSSION}

We first synthesized a series of copper(I)-based inorganic compounds with the $1 \mathrm{D}$ structure $\mathrm{CsCu}_{2} \mathrm{X}_{3}(\mathrm{X}=\mathrm{I}, \mathrm{Br}, \mathrm{Cl}$ and their mixtures). In short, the synthesis was carried out by simple dry ball milling of the corresponding $\mathrm{CsX}$ and $\mathrm{CuX}$ precursors in 1:2 molar ratios in inert atmosphere, in order to avoid hydration and possible oxidation (see supporting information for more details). Figure 2 shows the X-ray diffractograms of all samples in the $10^{\circ} \leq 2 \theta \leq 40^{\circ}$ range. All diffractograms are fitted assuming single-phase compounds crystallized in the $\mathrm{Cmcm}$ space group, with varying unit cell parameters (Figure $2 \mathrm{a}$ and Table S1). Unit cell volumes derived from the wholepattern fit show a rather linear expansion from $633 \AA^{3}(\mathrm{X}=\mathrm{Cl})$ to $840 \AA^{3}(X=I)$, as expected from the increased ionic radius when going from $\mathrm{Cl}^{-}$to $\mathrm{Br}^{-}$and to $\mathrm{I}^{-}$(Figure $2 \mathrm{~b}$ ). In order to better appreciate the phase-purity of the obtained compounds, experimental and fitted profiles are reproduced in higher resolution together with calculated Bragg's reflections in supporting information (Figures S1-S9). For monohalide compounds, the excellent quality of the fits is a strong indication of complete reaction and high phase purity. This observation also holds for most mixed-halide compounds, with a slightly worse match for Cl-rich mixed $\mathrm{Br}-\mathrm{Cl}$ compounds (Figure S7 and S8). In these two cases we cannot rule out a minor phase segregation between $\mathrm{CsCu}_{2} \mathrm{Br}_{3}$ and $\mathrm{CsCu}_{2} \mathrm{Cl}_{3}$ domains. Also, a broad peak around $2 \theta=31^{\circ}$ is observed in some samples that can be attributed to zirconia debris originating from the grinding medium. As this does not appear on all samples, we conclude that it is not unavoidable and probably a further optimization of the synthesis conditions (powder-to-ball weight ratio and previous use or not of the same grinding beads and jars) should result in a controllable elimination of these minor byproducts. 


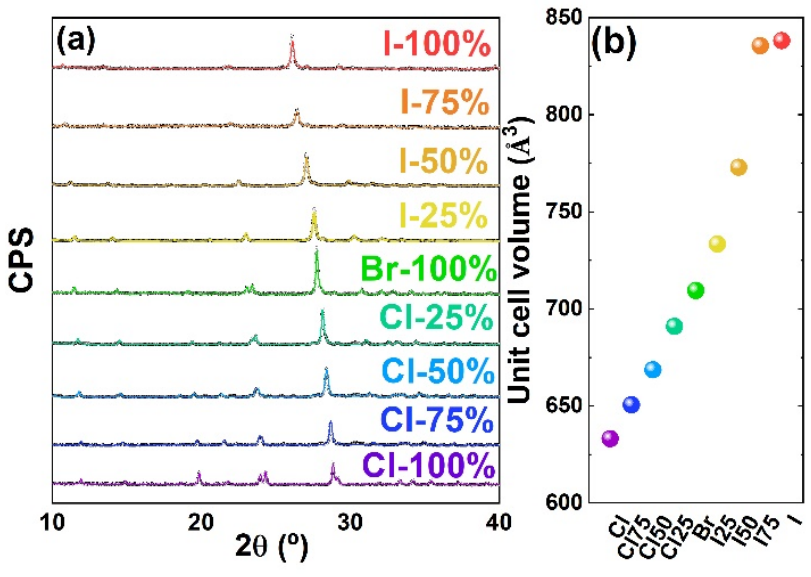

Figure 2. (a) XRD data (open circles) and fits (solid colored lines) of different $\mathrm{CsCu}_{2} \mathrm{X}_{3}$ compounds. (b) Unit cell volume as derived from fits.

Thermal stability of these materials was studied by thermogravimetric analyses (TGA). To the best of our knowledge, there are no previous references on the thermal stability of these materials. Yet, thermal stability is crucial at least for two reasons: (i) to determine whether the materials would remain stable in standard operation conditions once implemented in devices and (ii) to determine whether they can be processed by thermal processes such as thermal vacuum deposition, without undergoing incongruent melting or vaporization. The weight loss of the $\mathrm{CsCu}_{2} \mathrm{X}_{3}(\mathrm{X}=\mathrm{Cl}, \mathrm{Br}, \mathrm{I})$ compounds as a function of temperature at atmospheric pressure is reported in Figure S10. Bromide and iodide samples present the highest thermal stabilities of the series, without any weight variation until approximately $490^{\circ} \mathrm{C}$ and $360^{\circ} \mathrm{C}$, respectively. For the chloride species, the thermal behaviour is significantly different. A weight loss at around $185^{\circ} \mathrm{C}$ was observed, followed by an increase around $400^{\circ} \mathrm{C}$. Based on literature, these two features can be ascribed first to oxidation of the $\mathrm{Cu}(\mathrm{I})$ halide to $\mathrm{Cu}_{2} \mathrm{O}$, followed by the oxidation of $\mathrm{Cu}(\mathrm{I})$ oxide to $\mathrm{Cu}(\mathrm{II})$ oxide $\left(\mathrm{Cu}_{2} \mathrm{O} \rightarrow \mathrm{CuO}\right){ }^{26-28}$ These transformations might occur in the presence of residual oxygen in the TGA column, even if the analyses were performed with a nitrogen flow. For bromide and iodide samples, no weight increase was observed, pointing to their higher stability towards oxidation in the experimental conditions. Optical absorption shows a tunable onset around $305 \mathrm{~nm}-325$ nm (see Figure S11), however, no PL could be detected with our setup (see SI for details). This is in line with the literature, where only one recent report demonstrates weak PL (5\% PLQY) from surface-passivated colloidal nanorods with the same composition. ${ }^{11}$

We also investigated the $0 \mathrm{D}$ structures $\mathrm{Cs}_{3} \mathrm{Cu}_{2} \mathrm{X}_{5}(\mathrm{X}=\mathrm{Cl}, \mathrm{Br}$, I and mixtures thereof). The application of these compounds for optoelectronics has been scarcely studied before, with only the pure-bromide, pure-iodide and mixed bromide-iodide species being reported., ${ }^{9,10,12}$ The pure-chloride compound, in contrast, has been only reported to define its structure. ${ }^{29}$ Herein, we investigate the synthesis of the whole halide series by dry mechanochemistry and reveal their excellent optical quality.

Figure 3 and Figures S12-S20 show the XRD analysis of all $\mathrm{Cs}_{3} \mathrm{Cu}_{2} \mathrm{X}_{5}$ compounds. For all mixed iodide-bromide samples (including the pure bromide and the pure iodide ones), diffractograms are fitted considering a Pnma space group with varying unit cell parameters (Figure 3a). This analysis holds for chloride-containing samples up to a chloride content of $75 \mathrm{~mol} \%$. As a result, we observe a clear trend on the unit cell volume with the ionic radius of the halide anion $\left(\mathrm{Cl}^{-}<\mathrm{Br}^{-}<\mathrm{I}^{\text {; }}\right.$ see Figure $3 \mathrm{~b}$ and Table S2). While Pnma is the expected space group for all $\mathrm{Cs}_{3} \mathrm{Cu}_{2} \mathrm{I}_{5}, \mathrm{Cs}_{3} \mathrm{Cu}_{2} \mathrm{Br}_{5}$, and $\mathrm{Cs}_{3} \mathrm{Cu}_{2} \mathrm{Cl}_{5}$ based on ICSD (refs: 150298, 150297, and 150296 respectively), the diffractogram for $\mathrm{Cs}_{3} \mathrm{Cu}_{2} \mathrm{Cl}_{5}$ is better fitted considering the space group $\mathrm{Cmcm}$. Crystallization of $\mathrm{Cs}_{3} \mathrm{Cu}_{2} \mathrm{Cl}_{5}$ in this space group was already reported by others. ${ }^{29}$ While the crystallization in one or the other space group is evident by the fits obtained in both cases, we could not elucidate what drives the crystallization in a given structure here. This, as will be detailed hereafter has important consequences on the optical properties.

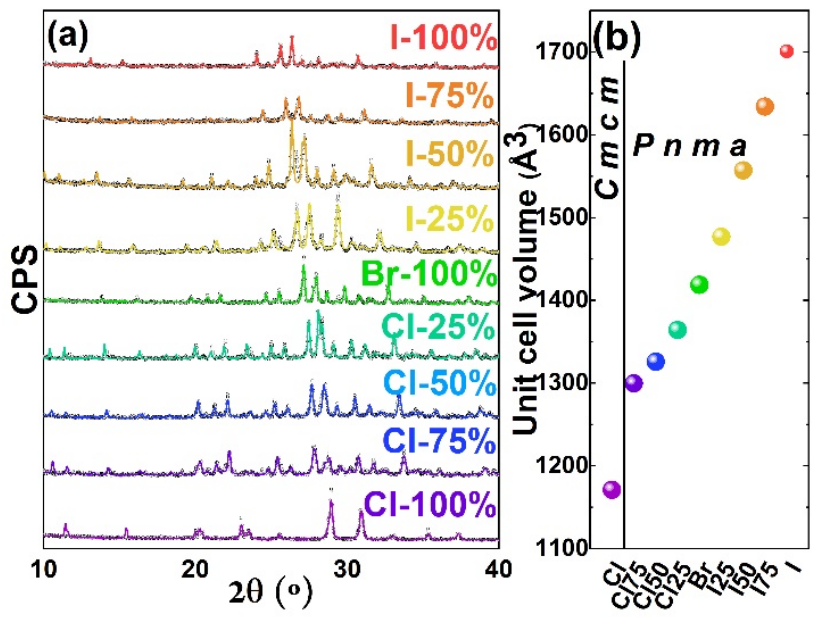

Figure 3. (a) XRD data (open circles) and fit (solid colored lines) of different $\mathrm{Cs}_{3} \mathrm{Cu}_{2} \mathrm{X}_{5}$ compounds. (b) Unit cell volume as derived from the fit.

By exposing these powders to air during 2-3 days, a change in their appearance is observed (see Fig. S21). For the chloride sample, we see a change in color to yellow similar to that of $\mathrm{Cu}(\mathrm{II})$ chlorides in solution $\left[\mathrm{CuCl}_{4}\right]^{2-30}$ consequence of oxidation in the presence of moisture. Interestingly, the XRD pattern shows significant differences after air exposure (see Fig. S22), which means that oxidation of the material affects the whole ("bulk") sample. In the case of bromide, we see a change of color similar to that of copper(II) bromides in solution, pointing again towards an oxidation by moisture and the formation of $\left[\mathrm{CuBr}_{4}\right]^{2-30}$ Nonetheless, for this compound it seems that the oxidation is only superficial, as no differences are observed by XRD (Fig. S22). In the case of the iodide analogous, we do not observe any difference, which agrees with the very low stability of $\mathrm{Cu}$ (II) iodide compounds. ${ }^{31,32}$ To further confirm these observations, we carried out X-ray Photoelectron Spectroscopy (XPS) and $\mathrm{X}$-ray-Excited Auger Electron Spectroscopy (XAES; Figure S23). While the $\mathrm{Cu} 2 \mathrm{p}$ spectra (Figure S23a) of $\mathrm{Cs}_{3} \mathrm{Cu}_{2} \mathrm{Br}_{5}$ and $\mathrm{Cs}_{3} \mathrm{Cu}_{2} \mathrm{I}_{5}$ show only a doublet for $\mathrm{Cu} 2 \mathrm{p}_{3 / 2}$ and $\mathrm{Cu} 2 \mathrm{p}_{1 / 2}$ peaks at binding energies (BEs) of $931.9 \mathrm{eV}$ and $951.8 \mathrm{eV}$ attributed to $\mathrm{Cu}(\mathrm{I})$, secondary high-BE peaks $933.9 \mathrm{eV}$ and $953.8 \mathrm{eV}$ are observed in $\mathrm{Cs}_{3} \mathrm{Cu}_{2} \mathrm{Cl}_{5}$, which are ascribed to the oxidation of copper into $\mathrm{Cu}$ (II) species in this sample, as previously described. ${ }^{33}$ This is furthermore confirmed 
by the presence of strong satellite peaks around $\mathrm{BE}=942 \mathrm{eV}$ and $\mathrm{BE}$ $=962 \mathrm{eV}$, which is a clear sign of $\mathrm{Cu}(\mathrm{II}) \cdot{ }^{33}$ Eventually, the higher Kinetic Energy of the $\mathrm{Cu}-\mathrm{LMM}$ Auger peak in $\mathrm{Cs}_{3} \mathrm{Cu}_{2} \mathrm{Cl}_{5}$ (Figure $\mathrm{S} 23 \mathrm{~b}$ ) again confirms the oxidation of copper into $\mathrm{Cu}$ (II) in this ma-

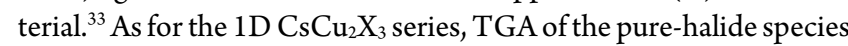
was carried out. The thermal behaviour was found to be similar to the $1 \mathrm{D}$ structures detailed above (see Fig. S25). We observe again a weight increase in the chloride sample, which suggests oxidation of these compounds. This is also in line with the structural analysis and colour change discussed above, where we noted a more favoured oxidation of the chloride samples. It must be noted, however, that all samples are stable until $250^{\circ} \mathrm{C}$, and even $350^{\circ} \mathrm{C}$ (bromide) and 450 ${ }^{\circ} \mathrm{C}$ (iodide).

Finally, we studied the optical properties of these materials (see Figure 4) by measuring the photoluminescence excitation (PLE) and emission (PL) spectra for the whole $\mathrm{Cs}_{3} \mathrm{Cu}_{2} \mathrm{X}_{5}$ series. The wavelengths at the maximum PL intensity and corresponding PLQY for all samples are detailed in Table 1 (note that the starting reagents do not show any noticeable PL under our measurement conditions as can be seen in Figure S24). Although the shifts in maximum excitation and emission wavelengths are not monotonic (see Figure S26 for more details), there is an overall red-shift in the PL when decreasing the halide ionic radius (from $\mathrm{I}^{-}$to $\mathrm{Cl}^{-}$). This behaviour is opposite to that observed from other MMHs such as LHPs or bismuth-based compounds. ${ }^{10,15,34-36}$ In fact, $\mathrm{PL}$ in those materials is a consequence of band-to-band radiative recombination, whereas for $\mathrm{Cs}_{3} \mathrm{Cu}_{2} \mathrm{X}_{5}$ the PL originates from self-trapped excitons induced by the strong charge localization within the $0 \mathrm{D}$ structure. ${ }^{10}$ Furthermore, we observe markedly different optical features for $\mathrm{Cl}$-rich compounds (75\% and $100 \%$ ), as compared to the rest of $\mathrm{Cs}_{3} \mathrm{Cu}_{2} \mathrm{X}_{5}$ materials (Figure 4). Indeed, $\mathrm{Cs}_{3} \mathrm{Cu}_{2} \mathrm{Cl}_{5}$ presents a significantly red-shifted $\mathrm{PL}$ spectrum with maximum emission wavelength around $516 \mathrm{~nm}$ (green), while iodide and bromide compounds typically show blue luminescence. This can be ascribed to the different crystalline phase of this compound as previously discussed (Figure 2). Interestingly $\mathrm{Cs}_{3} \mathrm{Cu}_{2}\left(\mathrm{Cl}_{0.75} \mathrm{Br}_{0.25}\right)_{5}$ compounds exhibits dual excitation and emission properties (see solid and dashed lines in Figure 4) suggesting the coexistence of the $\mathrm{Cmcm}$ phase (as $\mathrm{Cs}_{3} \mathrm{Cu}_{2} \mathrm{Cl}_{5}$ ) and Pnma phase (as $\mathrm{Cs}_{3} \mathrm{Cu}_{2} \mathrm{Br}_{5}$ ). It is possible that this phase segregation is linked to halide segregation, though we were unable to elucidate this hypothesis.

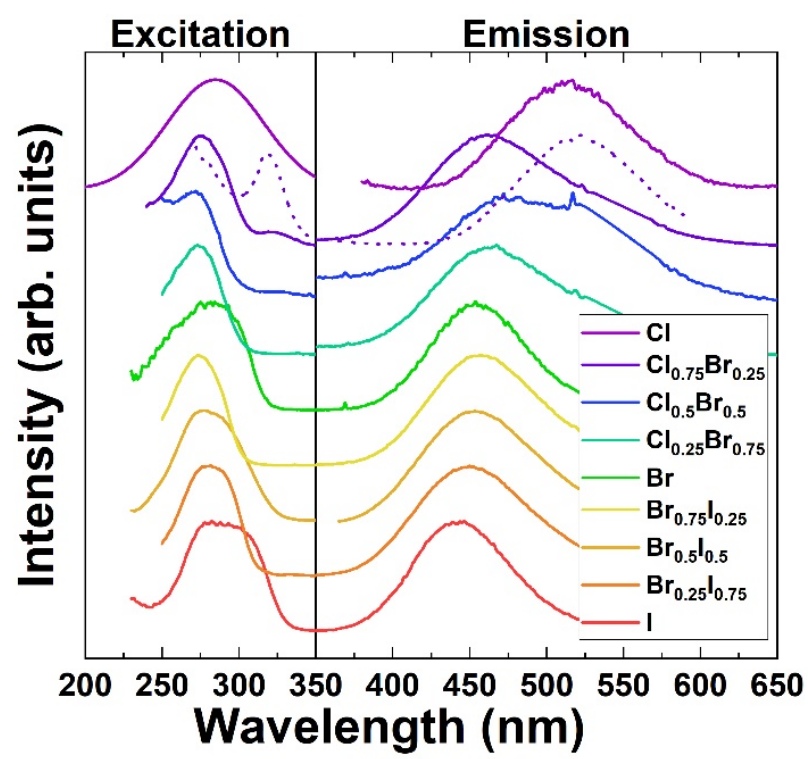

Figure 4. PLE (left) and PL (right) spectra of different $\mathrm{Cs}_{3} \mathrm{Cu}_{2} \mathrm{X}_{5}$. $\mathrm{X}$ given in the legend. For $\mathrm{Cs}_{3} \mathrm{Cu}_{2}\left(\mathrm{Cl}_{0.75} \mathrm{Br}_{0.25}\right)_{5}$ excitation spectrum corresponding to $516 \mathrm{~nm}$ emission and corresponding emission spectrum are presented as dashed lines, whereas excitation spectrum corresponding to emission at $450 \mathrm{~nm}$ and corresponding emission spectrum are presented as solid lines.

The PLQY of freshly-prepared pure-halides was found to be higher than that of all mixed-halide compounds (Table 1). Considering that the shift in the PL emission is minimal upon halide-mixing, no clear benefit (optical or structural) is obtained from mixed-compositions. Second, PLQY values of as-prepared pure-halide compounds are relatively high considering the simple synthesis conditions of dry ball-milling. Indeed, these values are comparable with those obtained from ligand-passivated quantum dots. ${ }^{10}$ It is especially worth highlighting the high PLQY of $78 \%$ for $\mathrm{Cs}_{3} \mathrm{Cu}_{2} \mathrm{Cl}_{5}$. We also observe that the PLQY of chloride and bromide compounds decreases significantly upon air exposure for $24 \mathrm{~h}$, while it is stable for $\mathrm{Cs}_{3} \mathrm{Cu}_{2} \mathrm{I}_{5}$. This effect is ascribed to the moisture-induced oxidation discussed before (Figs S21-S23), which does not occur for copper iodide. Losses in PLQY from air-exposure of bromide and chloride samples can nevertheless be recovered by thermal annealing for 40 minutes at $170{ }^{\circ} \mathrm{C}$, yielding PLQY values as high as $81 \%$ for $\mathrm{Cs}_{3} \mathrm{Cu}_{2} \mathrm{Cl}_{5}$.

Table 1. PLQY and $\lambda_{\mathrm{em}}$ for $\mathrm{Cs}_{3} \mathrm{Cu}_{2} \mathrm{X}_{5}$ compounds freshly prepared, exposed to air for $24 \mathrm{~h}$, and thermally annealed. For mixed-halide compounds, as no benefit was observed for freshly prepared samples, stability in air or upon annealing was not assessed.

\begin{tabular}{lll|ll|ll} 
& \multicolumn{2}{c|}{ As-prepared } & \multicolumn{2}{c|}{ Air-exposed } & \multicolumn{2}{c}{ Annealed } \\
\hline Compound & $\begin{array}{l}\lambda_{\text {em }} \\
(\mathrm{nm})\end{array}$ & $\begin{array}{l}\text { PLQY } \\
(\%)\end{array}$ & $\begin{array}{l}\lambda_{\text {em }} \\
(\mathrm{nm})\end{array}$ & $\begin{array}{l}\text { PLQY } \\
(\%)\end{array}$ & $\begin{array}{l}\lambda_{\text {em }} \\
(\mathrm{nm})\end{array}$ & $\begin{array}{l}\text { PLQY } \\
(\%)\end{array}$ \\
\hline $\mathrm{Cs}_{3} \mathrm{Cu}_{2} \mathrm{Cl}_{5}$ & 516 & 78 & 528 & 3 & 525 & 81 \\
$\mathrm{Cs}_{3} \mathrm{Cu}_{2}\left(\mathrm{Cl}_{0.75} \mathrm{Br}_{0.25}\right)_{5}$ & 516 & 10 & - & - & - & - \\
$\mathrm{Cs}_{3} \mathrm{Cu}_{2}\left(\mathrm{Cl}_{0.5} \mathrm{Br}_{0.5}\right)_{5}$ & 470 & 3.6 & - & - & - & - \\
$\mathrm{Cs}_{3} \mathrm{Cu}_{2}\left(\mathrm{Cl}_{0.25} \mathrm{Br}_{0.75}\right)_{5}$ & 464 & 3.2 & - & - & - & -
\end{tabular}




\begin{tabular}{lll|ll|ll}
$\mathrm{Cs}_{3} \mathrm{Cu}_{2} \mathrm{Br}_{5}$ & 455 & 14 & 456 & 3 & 457 & 19 \\
$\mathrm{Cs}_{3} \mathrm{Cu}_{2}\left(\mathrm{Br}_{0.75} \mathrm{I}_{0.25}\right)_{5}$ & 456 & 11 & - & - & - & - \\
$\mathrm{Cs}_{3} \mathrm{Cu}_{2}\left(\mathrm{Br}_{0.5} \mathrm{I}_{0.5}\right)_{5}$ & 452 & 15 & - & - & - & - \\
$\mathrm{Cs}_{3} \mathrm{Cu}_{2}\left(\mathrm{Br}_{0.25} \mathrm{I}_{0.75}\right)_{5}$ & 450 & 11 & - & - & - & - \\
$\mathrm{Cs}_{3} \mathrm{Cu}_{2} \mathrm{I}_{5}$ & 442 & 42 & 444 & 42 & 444 & 47
\end{tabular}

Given the promising optical features and stability of the pure-iodide compound in powder state, we attempted to deposit it as thin film. In order to do so, as a first approach we dissolved the material in organic solvents and subsequently spin-coated it on a glass substrate followed by thermal annealing (see Supporting information for details). The XRD pattern of spin-coated films show an excellent match with the reference ICSD pattern for bulk $\mathrm{Cs}_{3} \mathrm{Cu}_{2} \mathrm{I}_{5}$ (Fig. S27), suggesting that the structure is maintained upon thin film processing. Also the PL signal centred at $438 \mathrm{~nm}$ (Fig. S28) is very close to that of as-prepared bulk $\mathrm{Cs}_{3} \mathrm{Cu}_{2} \mathrm{I}_{5}$ powders (Table 1). The blue luminescence is characterized by a PLQY of $19 \%$, which is lower compared to that of the pristine bulk material. Although these results seem promising, it must be noted that dissolution of such inorganic metal halides in organic solvents is limited and as a result the film showed obvious inhomogeneities visible even to the naked eye (see Figure S29). Furthermore, using organic solvents for the thin film deposition partly defeats the purpose of using dry MCS for the original synthesis. Therefore, we tested the deposition of $\mathrm{Cs}_{3} \mathrm{Cu}_{2} \mathrm{I}_{5}$ by thermal single-source vacuum deposition. In short, as-synthesized powder materials are loaded in a ceramic crucible (source) inside a vacuum chamber. The source is then quickly heated to a high temperature by Joule effect causing the material to sublime and crystallize on the substrate, which is placed $c a .10 \mathrm{~cm}$ above the source (see Supporting Information for details). No further thermal annealing or other post-deposition treatment is required. This method has previously been shown to be promising for the deposition of LHP thin films. ${ }^{1724}$ The XRD signal of the film (Figure 5a) is well fitted considering the same space group as the bulk material. Interestingly, while all peaks present in the diffractogram of the film are present in the diffractogram of the powder sample (denoting that no impurity other than the expected $\mathrm{Cs}_{3} \mathrm{Cu}_{2} \mathrm{I}_{5}$ phase is present) the reciprocal is not true (i.e., several peaks present in the diffractogram of the powder sample are absent in the films'). Also, their relative intensities are varied. This, which is common for thin films of different compositions, ${ }^{37}$ can be attributed to a preferential crystallographic orientation (texture). The film thickness is measured to be $600 \mathrm{~nm}$. Scanning Electron Microscopy (SEM) shows good homogeneity with grains of different sizes in the range of hundreds of nanometers (Figure $5 \mathrm{~b}$ ). The homogeneity can also be assessed by lower magnification images (Figure S30). Eventually, we note that the optical excitation and emission spectra of the thin film are nearly identical to the ones of the starting bulk powders (Figure 5c). The PLQY of the vacuum-deposited film is $29 \%$, higher than the film formed by solutionprocessing and close to the value of the starting material. Hence, it is evident that SSVD of mechanochemically-synthesized cesium copper halides leads to thin films of excellent morphology, crystallinity, and optical properties, paving the way to the implementation of these fully-dry approaches for low-toxicity optoelectronics.
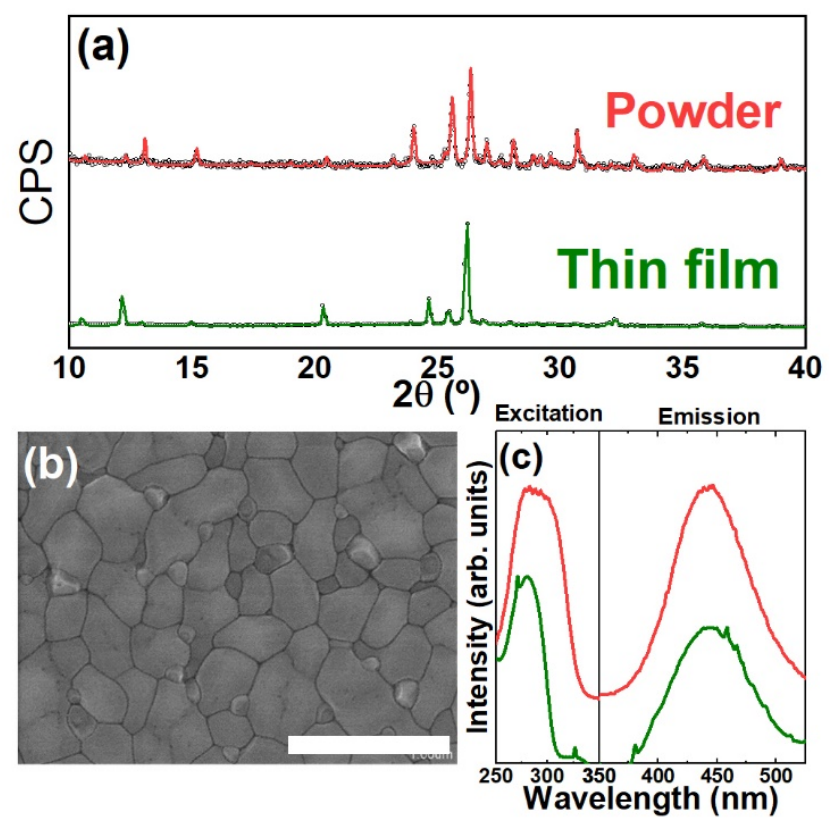

Figure 5. Characterization of SSVD $\mathrm{Cs}_{3} \mathrm{Cu}_{2} \mathrm{I}_{5}$ thin film. (a) X-ray diffractogram with Le Bail fit in green. For an easy comparison, data and fit from bulk powder (see Figure 3) is reproduced here in red. (b) Scanning electron microscopy image. Scale bar is 1 micron (see lower magnifications in Figure S30). (c) Photoluminescence excitation and emission spectra in green. For an easy comparison, data from bulk powder (see Figure 4) is reproduced here in red.

\section{CONCLUSIONS}

In summary, we have demonstrated the synthesis of $\mathrm{CsCu}_{2} \mathrm{X}_{3}$ and $\mathrm{Cs}_{3} \mathrm{Cu}_{2} \mathrm{X}_{5}(\mathrm{X}=\mathrm{Cl}, \mathrm{Br}$, I, and mixtures thereof) by simple solvent-free mechanochemistry. Pure-halide $\mathrm{Cs}_{3} \mathrm{Cu}_{2} \mathrm{X}_{5}$ compounds exhibit high $P L Q Y$ in the blue-green region of the visible spectrum, making these very promising materials for lighting or deep-UV photodetectors. The green-emitting $\mathrm{Cs}_{3} \mathrm{Cu}_{2} \mathrm{Cl}_{5}$ was synthesized with $78 \%$ PLQY ( $81 \%$ after air exposure and subsequent thermal annealing) albeit with poor stability in air. In contrast, the blue-emitting $\mathrm{Cs}_{3} \mathrm{Cu}_{2} \mathrm{I}_{5}$ achieved stable PLQY exceeding $40 \%$ even when stored in air for several days. Differences in spectral features have been rationalized in terms of different crystalline structures as evidenced by the wholepattern fitting of the XRD signal, while differences in air-stability can be explained by preferential oxidation mechanisms of $\mathrm{Cu}(\mathrm{I})$ halides to $\mathrm{Cu}(\mathrm{II})$ halides. Finally, we were able to process $\mathrm{Cs}_{3} \mathrm{Cu}_{2} \mathrm{I}_{5}$ powders into homogeneous thin films by single-source vacuum deposition with excellent crystallinity and conserved optical features. Future work will focus on the implementation of these films into different optoelectronic devices.

\section{ASSOCIATED CONTENT}

Supporting Information. This material is available free of charge via the Internet at http://pubs.acs.org.

Thermal characterization (TGA); absorbance spectra of $\mathrm{CsCu}_{2} \mathrm{X}_{3}$ compounds; change in color of $\mathrm{Cs}_{3} \mathrm{Cu}_{2} \mathrm{X}_{5}$ powders; XRD of 
non-exposed and exposed powders; variation in PLE and PL wavelengths of $\mathrm{Cs}_{3} \mathrm{Cu}_{2} \mathrm{X}_{5}$ powders; XRD and PL spectra of solution processed thin-films; SEM image of thin-film by SSVD of $\mathrm{Cs}_{3} \mathrm{Cu}_{2} \mathrm{I}_{5}$.

\section{AUTHOR INFORMATION}

\section{Corresponding Author}

*E-mail: francisco.palazon@uv.es

\section{ORCID}

Paz Sebastia-Luna: 0000-0001-6992-199X

Michele Sessolo: 0000-0002-9189-3005

Francisco Palazon: 0000-0002-1503-5965

Henk J. Bolink: 0000-0001-9784-6253

\section{Author Contributions}

The manuscript was written through contributions of all authors.

\section{Notes}

The authors declare no competing financial interest.

\section{ACKNOWLEDGMENT}

The research leading to these results has received funding from the European Union Programme for Research and Innovation Horizon 2020 (2014-2020) under the Marie Skłodowska-Curie Grant Agreement PerovSAMs No. 747599), the Spanish Ministry of Science, Innovation and Universities (ex-MINECO) via the Unidad de Excelencia Marı $\triangle a$ de Maeztu MDM-2015-0538, MAT2017- 88821-R, and PCIN-2015-255, and the Generalitat Valenciana (Prometeo/2016/135). M.S. thanks the Spanish Ministry of Science Innovation and Universities (exMINECO) for his postdoctoral RyC contract. We acknowledge the European Union's Horizon 2020 research \& innovation program under grant agreement No. 763977 of the PerTPV project. We thank Prof. Miguel Julve for fruitful discussions on the oxidation of copper halides.

\section{REFERENCES}

(1) Veldhuis, S. A.; Boix, P. P.; Yantara, N.; Li, M.; Sum, T. C.; Mathews, N.; Mhaisalkar, S. G. Perovskite Materials for Light-Emitting Diodes and Lasers. Adv. Mater. 2016, 28 (32), 6804-6834.

(2) Kitai, A. Chapter 5: Light Emitting Diodes. In Principles of Solar Cells, LEDs and Diodes; John Wiley \& Sons, Ltd, Chichester, 2011; pp 215252.

(3) Leijtens, T.; Bush, K. A.; Prasanna, R.; McGehee, M. D. Opportunities and Challenges for Tandem Solar Cells Using Metal Halide Perovskite Semiconductors. Nat. Energy 2018, 3 (10), 828-838.

(4) Xing, J.; Zhao, Y.; Askerka, M.; Quan, L. N.; Gong, X.; Zhao, W.; Zhao, J.; Tan, H.; Long, G.; Gao, L.; et al. Color-Stable Highly Luminescent Sky-Blue Perovskite Light-Emitting Diodes. Nat. Commun. 2018, 9 (1), 1-8.

(5) Xu, L. J.; Sun, C. Z.; Xiao, H.; Wu, Y.; Chen, Z. N. Green-LightEmitting Diodes Based on Tetrabromide Manganese(II) Complex through Solution Process. Adv. Mater. 2017, 29 (10), 2-6.

(6) Yang, T. C.-J.; Fiala, P.; Jeangros, Q.; Ballif, C. High-Bandgap Perovskite Materials for Multijunction Solar Cells. Joule 2018, 2 (8), 1421-1436.

(7) Bizzarri, C.; Spuling, E.; Knoll, D. M.; Volz, D.; Bräse, S. Sustainable Metal Complexes for Organic Light-Emitting Diodes (OLEDs). Coord. Chem. Rev. 2018, 373, 49-82.

(8) Li, X.; Zhong, X.; Hu, Y.; Li, B.; Sheng, Y.; Zhang, Y.; Weng, C.; Feng, M.; Han, H.; Wang, J. Organic-Inorganic Copper(II)-Based Material: A Low-Toxic, Highly Stable Light Absorber for Photovoltaic Application. J. Phys. Chem. Lett. 2017, 8 (8), 1804-1809.

(9) Jun, T.; Sim, K.; Iimura, S.; Sasase, M.; Kamioka, H.; Kim, J.; Hosono, H. Lead-Free Highly Efficient Blue-Emitting Cs3Cu2I5 with OD
Electronic Structure. Adv. Mater. 2018, 30 (43), 1-6.

(10) Roccanova, R.; Yangui, A.; Nhalil, H.; Shi, H.; Du, M.-H.; Saparov, B. Near-Unity Photoluminescence Quantum Yield in Blue-Emitting Cs $3 \mathrm{Cu} 2 \mathrm{Br} 5-\mathrm{x}$ I x $(0 \leq \mathrm{x} \leq 5)$. ACS Appl. Electron. Mater. 2019, 1, 269-274.

Cheng, P.; Sun, L.; Feng, L.; Yang, S.; Yang, Y.; Zheng, D.; Zhao, Y.; Sang, Y.; Zhang, R. Wei, D.; et al. Colloidal Synthesis and Optical Properties of All-Inorganic Low- Dimensional Cesium Copper Halide Nanocrystals. Angew. Chemie - Int. Ed. 2019.

Zhang, Z.; Li, C.; Lu, Y.; Tong, X.; Liang, F.-X.; Zhao, X.; Wu, D.; Xie, C.; Luo, L. Sensitive Deep Ultraviolet Photodetector and Image Sensor Composed of Inorganic Lead-Free $\mathrm{Cs}_{3} \mathrm{Cu}_{2} \mathrm{I}_{5}$ Perovskite with Wide Bandgap. J. Phys. Chem. Lett. 2019, acs.jpclett.9b02390.

(13) Rosales, B. A.; Wei, L.; Vela, J. Synthesis and Mixing of Complex Halide Perovskites by Solvent-Free Solid-State Methods. J. Solid State Chem. 2018, 271, 206-215.

(14) Protesescu, L.; Yakunin, S.; Nazarenko, O.; Dirin, D. N.; Kovalenko, M. V. Low-Cost Synthesis of Highly Luminescent Colloidal Lead Halide Perovskite Nanocrystals by Wet Ball Milling. ACS Appl. Nano Mater. 2018, 1 (3), 1300-1308.

El Ajjouri, Y.; Chirvony, V. S.; Vassilyeva, N.; Sessolo, M.; Palazon, F.; Bolink, H. J. Low-Dimensional Non-Toxic A $3 \mathrm{Bi}_{2} \mathrm{X}_{9}$ Compounds Synthesized by a Dry Mechanochemical Route with Tunable Visible Photoluminescence at Room Temperature. J. Mater. Chem. C 2019, 7 (21), 6236-6240.

(16) El Ajjouri, Y.; Chirvony, V. S.; Sessolo, M.; Palazon, F.; Bolink, H. J. Incorporation of Potassium Halides in the Mechanosynthesis of Inorganic Perovskites: Feasibility and Limitations of Ion-Replacement and Trap Passivation. RSC Adv. 2018, 8 (72), 41548-41551.

(17) El Ajjouri, Y.; Palazon, F.; Sessolo, M.; Bolink, H. J. Single-Source Vacuum Deposition of Mechanosynthesized Inorganic Halide Perovskites. Chem. Mater. 2018, 30, 7423-7427.

(18) El Ajjouri, Y.; Locardi, F.; Gélvez-Rueda, M. C.; Prato, M.; Sessolo, M.; Ferretti, M.; Grozema, F. C.; Palazon, F.; Bolink, H. J. Mechanochemical Synthesis of Sn(II) and Sn(IV) Iodide Perovskites and Study of Their Structural, Chemical, Thermal, Optical and Electrical Properties. Energy Technol. 2019, 1900788 (Ii), ente.201900788.

(19) Hong, Z.; Tan, D.; John, R. A.; Tay, Y. K. E.; Ho, Y. K. T.; Zhao, X.; Sum, T. C.; Mathews, N.; García, F.; Soo, H. Sen. Completely SolventFree Protocols to Access Phase-Pure, Metastable Metal Halide Perovskites and Functional Photodetectors from the Precursor Salts. iScience 2019, 312-325.

(20) Palazon, F.; El Ajjouri, Y.; Sebastia-Luna, P.; Lauciello, S.; Manna, L.; Bolink, H. J. Mechanochemical Synthesis of Inorganic Halide Perovskites: Evolution of Phase-Purity, Morphology, and Photoluminescence. J. Mater. Chem. C 2019, 7 (37), 11406-11410.

(21) Palazon, F.; Ajjouri, Y. El; Bolink, H. J. Making by Grinding: Mechanochemistry Boosts the Development of Halide Perovskites and Other Multinary Metal Halides. Adv. Energy Mater. 2019, 1902499, 1-13.

(22) Anastas, P.; Eghbali, N. Green Chemistry: Principles and Practice. Chem. Soc. Rev. 2010, 39 (1), 301-312.

(23) Ban, V.; Sadikin, Y.; Lange, M.; Tumanov, N.; Filinchuk, Y.; Černý, R.; Casati, N. Innovative in Situ Ball Mill for X-Ray Diffraction. Anal. Chem. 2017, 89 (24), 13176-13181.

(24) Crane, M. J.; Kroupa, D. M.; Roh, J. Y.; Anderson, R. T.; Smith, M. D.; Gamelin, D. R. Single-Source Vapor Deposition of Quantum-Cutting $\mathrm{Yb}^{3+}: \mathrm{CsPb}\left(\mathrm{Cl}_{1-x} \mathrm{Br}{ }_{x}\right)_{3}$ and Other Complex Metal-Halide Perovskites. ACS Appl. Energy Mater. 2019, 2, acsaem.9b00910.

(25) Longo, G.; Gil-Escrig, L.; Degen, M. J.; Sessolo, M.; Bolink, H. J. Perovskite Solar Cells Prepared by Flash Evaporation. Chem. Commun. 2015, 51 (34), 7376-7378.

(26) Sierra-Ávila, R.; Pérez-Alvarez, M.; Cadenas-Pliego, G.; Ávila-Orta, C. A.; Betancourt-Galindo, R.; Jiménez-Regalado, E.; Jiménez-Barrera, R. M.; Martínez-Colunga, J. G. Synthesis of Copper Nanoparticles Coated with Nitrogen Ligands. J. Nanomater. 2014, 2014, 1-8. 
(27) Vo Van, K.; Habashi, F. Identification and Thermal Stability of Copper(1) Sulfate. Can. J. Chem. 1972, 50, 3872.

(28) Li, J.; Shacham-Diamand, Y.; Mayer, J. W. Copper Deposition and Thermal Stability Issues in Copper-Based Metallization for ULSI Technology. Mater. Sci. Reports 1992, 9, 1-51.

(29) Mykhalichko, B. M.; Davydov, V. N.; Aksel'rud, L. G. Synthesis and Structure of Cs3Cu2Cl5. Russ. J. Inorg. Chem. 1997, 42 (7).

(30) Rizvi, M. A.; Akhoon, S. A.; Maqsood, S. R.; Peerzada, G. M. Synergistic Effect of Perchlorate Ions and Acetonitrile Medium Explored for Extension in Copper Redoximetry. J. Anal. Chem. 2015, $70(5), 633-638$.

(31) Margolis, L. A.; Schaeffer, R. W.; Yoder, C. H. The Synthesis and Analysis of Copper(I) Iodide. A First-Year Laboratory Project. J. Chem. Educ. 2009, 78 (2), 235.

(32) Burdett, J. K.; Sevov, S. Stability of the Oxidation States of Copper. J. Am. Chem. Soc. 1995, 117 (51), 12788-12792.

(33) Biesinger, M. C.; Lau, L. W. M.; Gerson, A. R.; Smart, R. S. C. Resolving Surface Chemical States in XPS Analysis of First Row Transition Metals, Oxides and Hydroxides: Sc, Ti, V, Cu and Zn. Appl.
Surf. Sci. 2010, 257 (3), 887-898.

(34) Sun, J.; Yang, J.; Lee, J. I.; Cho, J. H.; Kang, M. S. Lead-Free Perovskite Nanocrystals for Light-Emitting Devices. J. Phys. Chem. Lett. 2018, 9 (7), 1573-1583.

(35) Shin, J.; Kim, M.; Jung, S.; Kim, C. S.; Park, J.; Song, A.; Chung, K. B.; Jin, S. H.; Lee, J. H.; Song, M. Enhanced Efficiency in Lead-Free Bismuth Iodide with Post Treatment Based on a Hole-ConductorFree Perovskite Solar Cell. Nano Res. 2018, 11 (12), 6283-6293.

(36) Johansson, M. B.; Zhu, H.; Johansson, E. M. J. Extended PhotoConversion Spectrum in Low-Toxic Bismuth Halide Perovskite Solar Cells. J. Phys. Chem. Lett. 2016, 7 (17), 3467-3471.

(37) Palazon, F.; Pérez-del-Rey, D.; Dänekamp, B.; Dreessen, C.; Sessolo, M.; Boix, P. P.; Bolink, H. J. Room-Temperature Cubic Phase Crystallization and High Stability of Vacuum-Deposited Methylammonium Lead Triiodide Thin Films for High-Efficiency Solar Cells. Adv. Mater. 2019, 1902692, 1-6. 
Insert Table of Contents artwork here

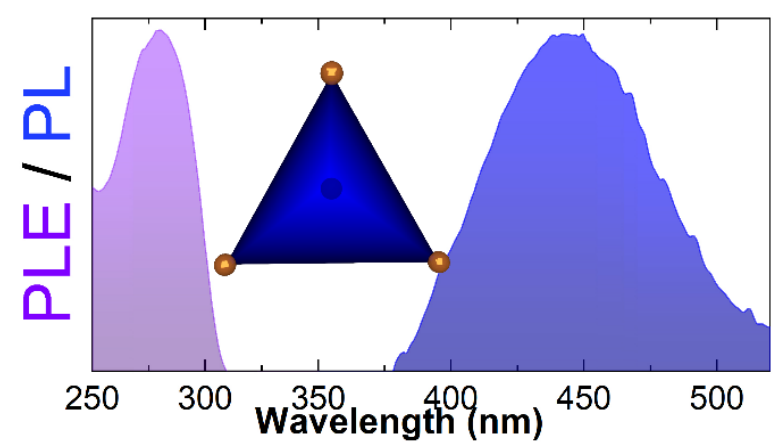

